\title{
Extracellular vesicles and its advances in female reproduction
}

\author{
Ana Clara Faquineli Cavalcante Mendes de Ávila ${ }^{1}$, Gabriella Mamede Andrade ${ }^{1}$, Alessandra Bridi ${ }^{1}$, \\ Lindsay Unno Gimenes ${ }^{2}$, Flávio Vieira Meirelles ${ }^{1}$, Felipe Perecin ${ }^{1}$, Juliano Coelho da Silveira ${ }^{1, \S}$
${ }^{1}$ Department of Veterinary Medicine, Faculty of Animal Sciences and Food Engineering, University of São Paulo, Pirassununga, SP, Brazil.
${ }^{2}$ Department of Preventive Veterinary Medicine and Animal Reproduction, School of Agricultural and Veterinarian Sciences, São Paulo State University (Unesp), Jaboticabal, SP, Brazil.

\begin{abstract}
Intercellular communication is an essential mechanism for development and maintenance of multicellular organisms. Extracellular vesicles (EVs) were recently described as new players in the intercellular communication. EVs are double-membrane vesicles secreted by cells and are classified according to their biosynthesis, protein markers and morphology. These extracellular vesicles contain bioactive materials such as miRNA, mRNA, protein and lipids. These characteristics permit their involvement in different biological processes. Reproductive physiology is complex and involves constant communication between cells. Different laboratories have described the presence of EVs secreted by ovarian follicular cells, oviductal cells, in vitro produced embryos and by the endometrium, suggesting that EVs are involved in the development of gametes and embryos, in animals and humans. Therefore, is important to understand physiological mechanisms and contributions of EVs in female reproduction in order to develop new tools to improve in vivo reproductive events and assisted reproductive techniques (ARTs). This review will provide the current knowledge related to EVs in female reproductive tissues and their role in ARTs.
\end{abstract}

Keyworks: extracellular vesicles, intercellular communication, female reproduction.

\section{Introduction}

Intercellular communication is an important reproductive physiology event. Cells that form reproductive tissues and structures are in constant interaction influenced by endocrine, paracrine and autocrine signaling (Albertini and Rider, 1994; Kretser et al., 2002). Besides the traditional forms of intercellular communication several studies have described extracellular vesicles (EVs) mediating the crosstalk between cells within or among tissues (da Silveira et al., 2012; Al-dossary et al., 2013; RuizGonzalez et al., 2015). Extracellular vesicles are nanoparticles secreted by different cell types (György et al., 2011; Raposo and Stoorvogel, 2013) and contains bioactive molecules such as mRNAs, microRNAs and proteins, which participate in the intercellular communication (Valadi et al., 2007; Simpson et al., 2008).

Extracellular vesicles secretion has been described in diverse reproductive cells as follicular cells (da Silveira et al., 2012), oviductal cells (Al-dossary et al., 2013), embryos produced in vitro (Mellisho et al., 2017) and endometrium cells ( $\mathrm{Ng}$ et al., 2013). Moreover, many reproductive physiological functions are associated with EVs. These functions include ovarian follicle development, oocyte maturation and fertilization, early embryo development and endometrial-conceptus crosstalk (da Silveira et al., 2012; Al-dossary et al., 2013; Ruiz-Gonzalez et al., 2015; Hung et al., 2015; Lopera-vásquez et al., 2016). Moreover, EVs has also emerged as a potential in vitrotool to improve assisted reproductive techniques (ARTs).

Assisted reproductive techniques are frequently used in animals and humans (Sirard, 2018). The principals of its use are to improve reproductive efficiency and as an alternative to infertility (Bousquet et al., 1999). However, exposure of gametes and early embryos to the in vitro environment influences embryo quality, RNA expression and ultrastructure patterns (Rizos et al., 2002a,b). These changes could cause pregnancy losses and can affect the health of generated individuals (Urrego et al., 2014; Bouillon et al., 2016). Therefore, is important to understand the physiological events in order to improve ARTs by mimicking in vitro the physiological conditions.

In summary, ARTs are important reproductive techniques; however, the in vitro environment can negatively affect gametes, embryo development and pregnancy establishment. One of the reasons is related to the lack of physiological mechanisms such as intercellular communication. Extracellular vesicles are carriers of molecules and were demonstrated to affect follicle development, oocyte maturation, embryo production and endometrial-conceptus communication. Then, this review will demonstrate the main studies describing EVs related to female reproductive tract and their impact in ARTs.

\section{Extracellular vesicles characterization}

Extracellular vesicles (EVs) are membrane vesicles formed by a lipid bilayer that are secreted by cells (Théry et al., 2009). They are found in body fluids and include exosomes, microvesicles and apoptotic bodies (György et al., 2011). Extracellular vesicles types can be differentiated by size, biosynthesis and contents. These membrane vesicles are released in the extracellular environment in response to specifics 
stimulus in physiological or pathological situations (Cocucci et al., 2009; El Andaloussi et al., 2013; Tannetta et al., 2014). The collection and study of only one subtype of EVs is still a challenge due to the lack of specific markers and protocols for isolation (Gould and Raposo, 2013; Lötvall et al., 2014). Thus, it is recommended to use the term extracellular vesicles.

Exosomes are small EVs between $30-150 \mathrm{~nm}$ in diameter (György et al., 2011). Its biosynthesis involves the formation of multivesicular bodies (MVBs) from a first plasma membrane endocytosis, forming the early endosome. Intraluminal vesicles (ILV) are formed into MVB and are released in the extracellular environment after the fusion of MVB with the plasma membrane (Théry et al., 2002; 2009). This mechanism was described firstly during in vitro maturation of reticulocytes (Harding et al., 1983; Pan et al., 1985). Differently, microvesicles are large EVs between 100$1000 \mathrm{~nm}$ in diameter formed from plasma membrane blebbing in response to stimulus or stress (Cocucci et al., 2009; Tannetta et al., 2014). Apoptotic bodies are heterogeneous vesicles, from $1-5 \mu \mathrm{m}$ originated from apoptotic processes and contain organelles and nuclear fragments (Pavani et al., 2017). Curiously, new subpopulations of nanoparticles were described in a recent study (Zhang et al., 2018). They were termed small exosomes vesicles $(60-80 \mathrm{~nm})$, large exosomes vesicles $(90-120 \mathrm{~nm})$ and exomeres $(\sim 35 \mathrm{~nm})$ (Zhang et al., 2018). The study suggested distinct biological function for each subsets of nanoparticles, since its different biodistribution patterns (Zhang et al., 2018).

Despite the divergences in nomenclature between the subtypes of EVs, exosomes and microvesicles have important roles in biological processes and have been largely studied. Extracellular vesicles, such as exosomes and microvesicles, have bioactive material such as mRNA and microRNAs (Valadi et al., 2007), proteins (Simpson et al., 2008) and lipids (Subra et al., 2007). These components suggest their cell modulating functions. Additionally, the mechanism of communication between EVs and target cell include, briefly: 1) Interaction between membrane proteins activating intracellular signaling within target cells; 2) Cleavage of membrane exosomal proteins near to target cell receptors; 3) molecular transfer of EVs contents by fusion with target cell and 4) EVs phagocytosis by recipient cells (Mathivanan et al., 2010; El Andaloussi et al., 2013).

Extracellular vesicles can be obtained from extracellular fluids derived from culture media or body fluids (Lötvall et al., 2014). Several methods for isolation are in constant discussion. The ideal method can vary according to the question to be answered, application, purity and desired concentration (Witwer et al., 2013; Lötvall et al., 2014). The appropriated methods for EVs isolation and analysis are standardized by the International Society for Extracellular Vesicles (ISEV). Usually, the techniques to isolate EVs are ultracentrifugation, filtration, polymer precipitation, immunoaffinity and microfluidic techniques (Witwer et al., 2013). The analysis of isolated products can be quantitative and qualitative. It can be realized by electronic and atomic force microscopy, optical particle tracking, flow cytometry and western blotting; to evaluate morphology, size, concentration, purity and protein content, respectively (Witwer et al., 2013).

\section{Small extracellular vesicles in female reproduction}

Since the observations of small EVs in intercellular communication, many studies have shown the influence of these vesicles in reproductive processes. In this context, small EVs were described in follicular fluid (da Silveira et al., 2012), oviductal fluid (Al-dossary et al., 2013), secreted by embryos in culture media (Kropp et al., 2014; Kropp and Khatib, 2015a; b) and in endometrium flushing ( $\mathrm{Ng}$ et al., 2013). Additionally, the knowledge of molecular mechanisms implicating EVs is favoring the development of new technologies involving biological roles, diagnostic and therapeutic potential (Saadeldin et al., 2015).

\section{Extracellular vesicles in ovarian follicle environment}

The ovarian follicle is an important structure within the ovary. This microenvironment is composed by theca cells, granulosa cells, cumulus cells and the oocyte (reviewed by Knight and Glister, 2006). During the folliculogenesis, antral follicles are characterized by the presence of follicular fluid (reviewed by Edson et al., 2009). The follicle microenvironment is regulated by endocrine, paracrine and autocrine factors during its development (Albertini and Rider, 1994; Matsuda et al., 2012). Therefore, the intercellular communication within this microenvironment is essential for oocyte and follicle development. Additionally, follicular cells can secrete EVs, found in follicular fluid, which transmit information between cells (Andrade et al., 2017; Fig. 1I).

Small EVs were firstly described in follicular fluid of mares (da Silveira et al., 2012). In this study, it was confirmed the small EVs uptake by granulosa cells in vivo and in vitro. In addition, different miRNAs were found in small EVs of young and old mares (da Silveira et al., 2012). Interestingly, different miRNAs contents were also observed in small EVs from follicular fluid of young and older women (Diez-Fraile et al., 2014). Sohel et al. (2013) described the proportion of miRNAs contents within different follicular fluid fractions. This group demonstrated for the first time that the majority of miRNAs from follicular fluid were in the exosomes fraction (Sohel et al., 2013), which emphasizes the importance of studying EVs miRNA contents. Furthermore, this study showed that exosome uptake by follicular cells was associated with an increase in miRNAs levels in these cells (Sohel et al., 2013).

Additionally, the communication mechanisms and effects of small EVs from follicular fluid, granulosa cells and COCs are under investigation. Exosomes from follicular fluid were involved in regulate TGF-beta (transforming growth factor beta) signaling pathway, an important pathway related to follicular development, in granulosa cells (da Silveira et al., 2014). This study showed that exosomes regulate members of TGF-beta 
pathways such as ACVR1 (activin A receptor type 1) and ID2 (inhibitor of DNA binding 2) in granulosa cells in vitro by transferring mRNA, protein and miRNAs (da Silveira et al., 2014). Recent studies demonstrated that EVs from bovine follicular fluid from small follicles (3$5 \mathrm{~mm}$ in diameter) and large follicles $(>9 \mathrm{~mm}$ in diameter) induce cumulus expansion during in vitro maturation (Hung et al., 2015). Importantly, this study demonstrated a better effect by EVs isolated from small follicles. Additionally, EVs from small follicles supplemented during COCs in vitro maturation induced changes in embryo transcripts levels, increase in blastocyst rates, as well as changes in global levels of DNA methylation and hydroxymethylation (da Silveira et al., 2017).

Other studies demonstrated that EVs characterization change according to follicle dimension (Navakanitworakul et al., 2016; Hung et al., 2017). Extracellular vesicles concentration and its miRNA contents are modified between small, medium and large bovine follicles (Navakanitworakul et al., 2016). Moreover, this study suggests changes in biogenesis or in EVs uptake during follicle development. This information was confirmed since the uptake of EVs from small follicles by granulosa cells was preferential, comparing to medium and large follicles EVs (Hung et al., 2017). The differences found between EVs from small and large follicles are related to increased granulosa cell proliferation after EVs supplementation from small antral follicles comparing to large follicles (Hung et al., 2017).

In summary, it is clear that EVs from follicular fluid have important contents related to biological processes during follicle and oocyte development. As an example, it is possible to detect effects from these EVs in cumulus and granulosa cells (Hung et al., 2015, 2017). These studies increased our understanding regarding reproductive biology processes as well as the possibility of using these EVs to improve oocyte in vitro maturation in many species. However, the follicle environment undergoes hormonal and developmental modifications that can change EVs biogenesis and contents, thus is important to consider ovarian follicle physiology in order to improve the use of EVs in the assisted reproductive techniques.

\section{Extracellular vesicles in the oviduct environment}

The oviduct is an important part of the female reproductive organ located between ovary and uterus (Hunter, 2012). After ovulation, the oocyte goes to the oviduct, where it undergoes fertilization and early embryo development in mammals (Spencer et al., 2007). The mammalian oviduct epithelium is composed by ciliated and secretory cells that are involved in these processes (Eriksen et al., 1994). These cells participate in secretion of oviductal fluid that has important roles in oocyte competence and embryo development (Leese et al., 2008; Avilés et al., 2010). Extracellular vesicles are one of the components of the oviductal fluid that favor oocyte and embryo quality (Lopera-vásquez et al., 2016; Fig. 1-II).
The presence of EVs in the oviductal fluid was described for the first time in murine and it was called "oviductosomes" (Al-dossary et al., 2013). Al-dossary et al. (2013) showed that murine oviductosomes contain a membrane protein called Plasma Membrane $\mathrm{Ca} 2+$ ATPase 4 (PMCA4) that play roles in sperm capacitation, and subsequently in fertilization. Additionally, this study demonstrated in vitro the uptake of exosomal PMCA4 by sperm cells, suggesting an important role for these vesicles during fertilization.

In the beginnings of IVF different laboratories used oviductal cells in co-culture with embryos to mimic the beneficial effects of in vivo system (Eyestone and First, 1989). However, these techniques presented some disadvantages such as undefined culture conditions, embryo and somatic cells competition for nutrients as well as risk of diseases transmission (Orsi and Reischl, 2007). Thus, conditioned medium and EVs could serve as alternatives to co-culture components (Maillo et al., 2016). Moreover, the study of the EVs contents could lead to the use of specific donor cells or to the development of synthetic or semi synthetic vesicles to transport components of interest in order to mimic the maternal environment.

Proteomic profile of EVs secreted by bovine oviduct epithelial cells (BOEC) in vivo or in vitro presents important differences (Almiñana et al., 2017). In vivo collected EVs presented proteins related with fertilization and early pregnancy development, like oviductal glycoprotein (OVGP), heat shock protein A8 (HSPA8) and myosin 9 (MYH9). However, the BOECs submitted to in vitro system did not present OVGP (Almiñana et al., 2017), an important protein associated with zona pellucida maturation (Avilés et al., 2010). Therefore, these studies suggest that the in vitro system can affect oviductal EVs contents.

Extracellular vesicles supplementation to embryo culture media demonstrated functional effects in early embryo development (Lopera-vásquez et al., 2016; Almiñana et al., 2017). Additionally, it was demonstrated that in vitro produced embryos can internalize oviductal EVs (Almiñana et al., 2017; Pavani et al., 2017). Although, frozen collected oviductal EVs supplemented to in vitro culture media, improves in vitro blastocyst yield and quality in comparison with fresh oviductal EVs and negative control (without EVs; Almiñana et al., 2017). Similarly, EVs from BOEC were able to reproduce the beneficial effects of oviduct cells conditioned medium, suggesting its use as an alternative supplementation for embryo development culture media (Lopera-vásquez et al., 2016). Embryos treated with EVs from BOEC culture media presented greater number of total cells and better survival rate after vitrification in comparison with embryos cultured without EVs (Lopera-vásquez et al., 2016). Additionally, this study demonstrated a greatest relative expression of PAG1 (Phosphoprotein Membrane Anchor with Glycosphingolipid Microdomains 1), an implantation related gene, in embryos supplemented with EVs. Specifically, oviductal fluid derived EVs from isthmus resulted in greatest bovine embryo survival rate after vitrification 
comparing with EVs from ampulla or in absence of EVs (Lopera-Vasquez et al., 2017). The improvement in embryo quality can be associated to the level of $A Q P 3$ (Aquaporin 3), a water channel, that was upregulated in embryos supplemented with EVs from isthmus comparing with embryos supplemented with FCS only (Lopera-Vasquez et al., 2017).

In conclusion, oviductal derived EVs have a role during embryo early development. This communication can favor fertilization and embryo quality. Then, EVs from oviduct are possible tools to improve in vitro culture system. However, it is important to consider the physiological modifications in EVs contents according to oviduct origin in vivo or in vitro as well as the region of oviduct used to obtain these EVs. These concerns are important to understand the role of these EVs during biological processes such as fertilization and early embryo development aiming to use these EVs properly in different ARTs.

\section{Extracellular vesicles in embryo in vitro production}

Embryos produced in vitro are exposed to different conditions in comparison with the in vivo oviductal and uterine environment. These in vitro conditions are responsible for many embryonic alterations, including morphological, metabolic, developmental and molecular changes (Plante and King, 1994; Holm and Callesen, 1998; Lonergan et al., 2003). Based on that, is important to investigate in vitro embryo derived EVs in order to understand the consequences of the in vitro environment. The first evidence of embryo derived EVs was demonstrated by the co-culture of porcine parthenogenetic (PA) and somatic cell nuclear transference (SCNT) embryos (Saadeldin et al., 2014). Pluripotency transcripts such as octamer-binding transcription factor (OCT4), sex determining region Y-box 2 (SOX2), avian myelocytomatosis viral oncogene homolog $(C-M Y C)$ and homeobox transcription factor nanog (NANOG) were present in exosomes secreted by porcine PA embryos, suggesting that co-culture of embryos could create a microenvironment, thus improving SCNT embryo development (Saadeldin et al., 2014).

Moreover, SCNT embryos also secrete exosomes in the medium during in vitro culture. Supplementation with exosomes secreted by SCNT embryos in the culture medium of SCNT embryos increases blastocyst rate, total cell numbers, ratio of $\mathrm{ICM} / \mathrm{TE}$ as well as transcripts levels of $O C T-4$ in comparison to SCNT embryos without supplementation ( $\mathrm{Qu}$ et al., 2017). These findings indicated that exosomes present in the culture medium are essential for embryo development and changes caused during embryo development by culture medium replacement may be repaired by exosome supplementation $(\mathrm{Qu}$ et al., 2017). Thus, in vitro embryo derived EVs may modulate in vitro conditions creating a microenvironment that favors embryonic development. Additionally, embryo derived EVs could serve as noninvasive marker correlated with embryo quality.
Extracellular vesicles in endometrial-conceptus crosstalk

Since early pregnancy stages, the establishment of cross communication between embryo/conceptus and the maternal organism is necessary. The endometrium is formed by epithelial and glandular cells capable to secrete nutrients and growth factors essential for early embryonic development (Bazer et al., 2011). Additionally, in ruminants, conceptus secreted interferontau (IFNT) is a protein responsible for signaling conceptus presence inside the maternal uterus during maternal recognition of pregnancy (Farin et al., 1990).

Extracellular vesicles are part of this cross communication important for maternal recognition of pregnancy (Tannetta et al., 2014). During preimplantation period conceptus and maternal endometrium can secrete EVs (Saadeldin et al., 2015; Fig. 1- III). In order to test that, on day 14 of pregnancy, uterine flush (UF) derived EVs were labeled with PKH67 and infused back in the pregnant uterus. Upon collection of tissues, conceptus trophoblast and uterine epithelia contained labeled EVs, suggesting the role of EVs in the cross communication between those cells at the onset of pregnancy (Burns et al., 2016). Similarly, uterine epithelial cells can secrete EVs containing ovine endogenous jaagsiekte retroviruses (enJSRV) mRNA (Ruiz-González et al., 2015). Free and exosomal enJSRV act via toll-like receptors $(T L R)$ on the conceptus trophectoderm cells (oTr1) to induce interferon-tau (IFNT) secretion (Ruiz-González et al., 2015). Trophoblast CT-1 cells treated with exosomes from uterine flushing of pregnant cows on Days 17, 20 and 22 did not change IFNT and caudal type homeobox 2 $(C D X 2)$ transcripts levels, suggesting an influence of the pregnancy period on the components of the EVs (Kusama et al., 2018).

Moreover, ovine conceptus trophectoderm derived exosomes, with 15 and 17 days of pregnancy, have IFNT, macrophage-capping protein (CAPG) as well as aldo-keto reductase family 1, member B1 protein (AKR1B1) (Nakamura et al., 2016). Similarly, exosomes secreted by ovine and bovine conceptus containing IFNT were able to increase interferonstimulated genes (ISGs) mRNA expression in primary uterine endometrial epithelial cells (EECs) (Nakamura et al., 2016; Kusama et al., 2018). Endometrial epithelial cells treated with exosomes at preimplantation period (P17 UFs) increased the expression of apoptosis - related genes such as BCL2 associated X, apoptosis regulator $(B A X)$, caspase $3(C A S P 3)$, tumor necrosis factor (TNFA) and tumor protein P53 (TP53) transcripts (Kusama et al., 2018). Besides that, exosomes at post-implantation (P20 and P22 UFs) stimulate adhesion molecules such as vascular cell adhesion molecule 1 (VCAM1) mRNA (Kusama et al., 2018). These results demonstrate that changes in the uterine environment mediated by exosomes are required for attachment and development of the conceptus.

Progesterone and estradiol hormone can influence the secretion of exosomes by endometrial 
cells in human (Greening et al., 2016). Progesterone is needed for elongation and survival of ovine conceptus (Spencer and Bazer, 2002). Thus, EVs number increases from Day 10 to 14 post-estrus in the ovine uterine lumen (Burns et al., 2018). Moreover, progesterone treatment increased the EVs number in the uterine lumen in comparison with a P4 receptor antagonist group (Burns et al., 2018). MiRNAs upregulated by progesterone in ovine uterine EVs are predicted to modulate pathways such as $\mathrm{PI} 3 \mathrm{~K} / \mathrm{AKT}$, bone morphogenetic proteins $(B M P)$ and post-transcriptional silencing by small RNAs (Burns et al., 2018). These findings indicate a new way by which $\mathrm{P} 4$ may modulate endometrial function controlling conceptus growth during pregnancy establishment.

On Day 20 of pregnancy, EVs were identified in the porcine endometrium and chorioallantoic membrane (Bidarimath et al., 2017). Porcine trophectoderm derived EVs induce aortic endothelial cells proliferation, which may be stimulating angiogenesis (Bidarimath et al., 2017). Furthermore, porcine trophectoderm and aortic endothelial cells EVs have miRNAs predicted to modulate angiogenesis and placental development pathways, suggesting that these EVs may play an important role in the communication between conceptus and maternal endometrium influencing the establishment of pregnancy (Bidarimath et al., 2017). Therefore, factors such as hormones and the day of pregnancy can change EVs secretion and contents in the uterine environment. Based on that, is important to understand the mechanisms modulating uterine EVs, which can impact protein, mRNA and miRNAs contents involved in important biological processes during early pregnancy in the different domestic species. Finally, uterine EVs may play important role in endometrial-conceptus cross-talk in the period of maternal recognition of pregnancy and might be involved in pregnancy success.
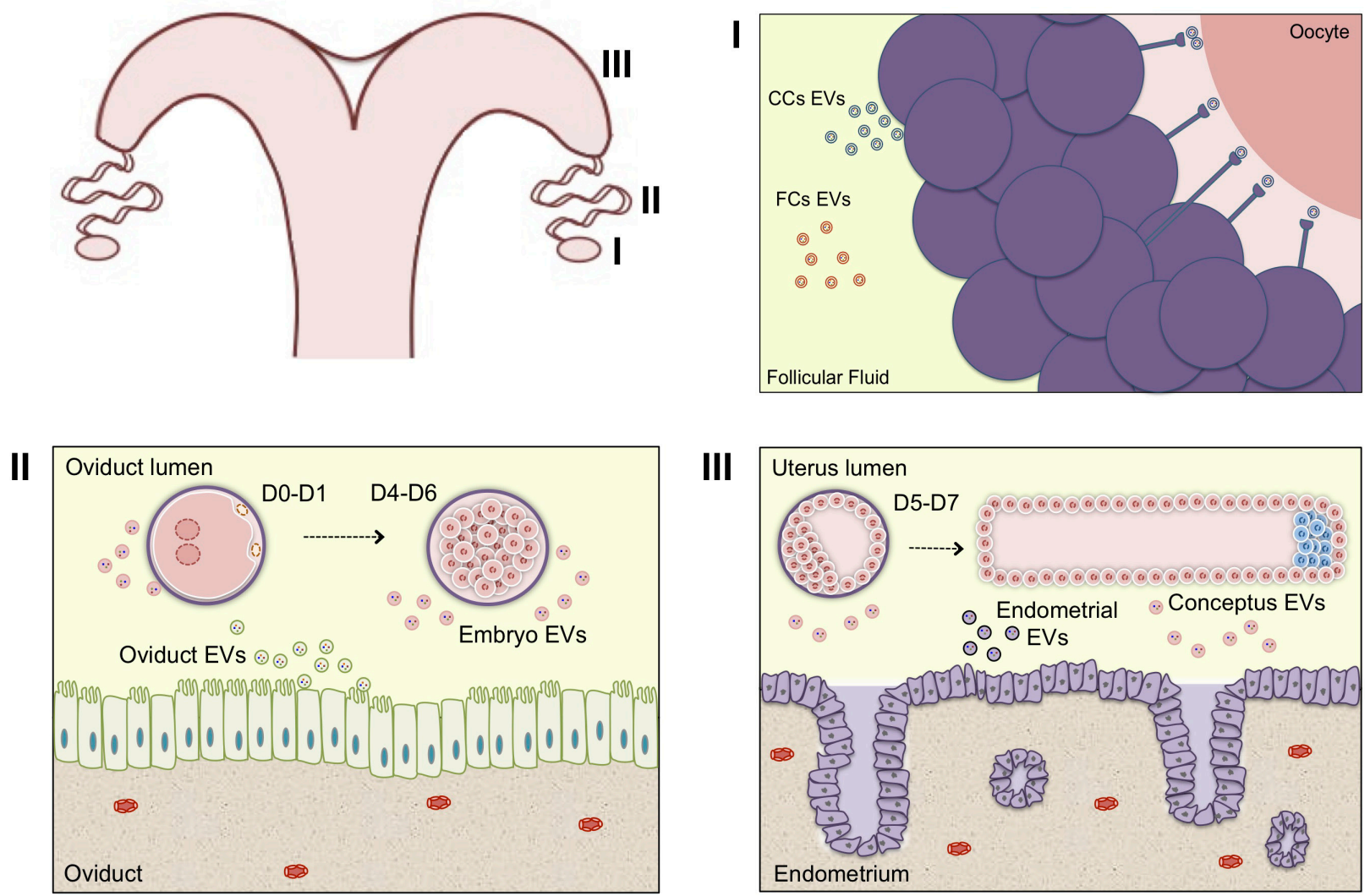

Figure 1. Extracellular vesicles in female reproduction. Schematic representation of extracellular vesicles present within the ovarian follicular microenvironment, as well as during the embryonic development within the oviduct and uterus. (I) Extracellular vesicles in the follicular fluid can carry and transfer bioactive molecules such as proteins, RNAs, miRNAs, lipids and metabolites contributing to oocyte maturation process, (II) to fertilization and embryonic early development in the oviductal microenvironment (III) as well as during the maternal recognition within the uterine microenvironment. Legend: EVs - extracellular vesicles; CCs - cumulus cells; FCs - follicular cells; D0 fertilization day.)

\section{Perspectives}

Since the discoveries of EVs biological functions, many studies have been conducted exploring their biosynthesis, contents, interaction with recipient cells as well as methods for isolation and characterization. Thus, is important to clarify the involvement of EVs in physiology and pathological processes. Additionally, EVs have potential as new biomarkers and therapeutics. Different studies are 
exploring the inhibition of EVs formation, release and uptake by recipient cells, as well as their potential in therapeutic (El Andaloussi et al., 2013). However, we still have challenges on these subjects. Despite the challenges, the development of synthetic and semisynthetic vesicles might be the mechanism to use these EVs in vivo and in vitro. Extracellular vesicles are considered a new biological strategy to reach cells and deliver nucleic acids with increased specificity (Nguyen and Szoka, 2012). Despite the good perspectives for the clinical application of EVs, the success depends on EVs time of processing, the small volumes of fluids, the knowledge regarding EVs trafficking and functions on the in vivo environment (Hood and Wickline, 2012).

In the reproduction scenario, synthetic or semisynthetic EVs are yet to be developed. However, since their description in reproductive fluids, many researches have demonstrated cross communication involving EVs as well as the contents such as miRNAs, mRNAs and proteins in different reproductive biofluids. Therefore, is important to increase our knowledge regarding the EVs biology in reproductive tissues in order to generate new approaches to improve fertility. The goal will be to create a better environment to produce embryos in vitro and consequently generate healthier pregnancies in animals and humans.

\section{Acknowledgments}

The authors are thankful to the University of São Paulo; the São Paulo Research Foundation FAPESP (grant number \#2014/22887-0 (JCS), \#2017/02037-0 (ACFCMA) and \#2018/01431-9 (GMA)); the National Council for Scientific and Technological Development - CNPq (grant number \#306349/2017-5 (FP)) and the Coordination for the Improvement of Higher Education Personnel (CAPES).

\section{References}

Al-dossary AA, Strehler EE, Martin-deleon PA. 2013. Expression and secretion of plasma membrane $\mathrm{Ca}$ 2 + - ATPase 4a ( PMCA4a ) during murine estrus: Association with Oviductal Exosomes and Uptake in Sperm. PLoS ONE, 8:e80181. doi: 10.1371/journal.pone.0080181. eCollection 2013.

Albertini DF, Rider V. 1994. Patterns of intercellular connectivity in the mammalian cumulus-oocyte complex. Microsc Res Tech, 133:125-133.

Almiñana C, Corbin E, Tsikis G, Alcântara-Neto AS, Labas V, Reynaud K, Galio L, Uzbekov R, Garanina AS, Duart X, Mermillod P, 2017. Oviduct extracellular vesicles protein content and their role during oviduct-embryo cross-talk. Reproduction, 154:153-168.

Andrade G, Meirelles F, Perecin F, da Silveira J. 2017. Cellular and extracellular vesicular origins of miRNAs within the bovine ovarian follicle. Reprod Domest Anim, 52:1036-1045.

Avilés M, Gutiérrez-Adán A, Coy P. 2010. Oviductal secretions: Will they be key factors for the future ARTs? Mol Hum Reprod, 16:896-906.
Bazer FW, Wu G, Johnson GA, Kim J, Song G. 2011. Uterine histotroph and conceptus development: select nutrients and secreted phosphoprotein 1 affect mechanistic target of rapamycin cell signaling in ewes. Biol Reprod, 85:1094-1107.

Bidarimath M, Khalaj K, Kridli RT, Kan FWK, Koti M, Tayade C. 2017. Extracellular vesicle mediated intercellular communication at the porcine maternal-fetal interface: A new paradigm for conceptusendometrial cross-talk. Sci Rep, 7:40476.

Bouillon C, Léandri R, Desch L, Ernst A, Bruno C. 2016. Does embryo culture medium influence the health and development of children born after in vitro fertilization? PLoS ONE, 11:e0150857. doi: 10.1371/journal.pone.0150857. eCollection 2016.

Bousquet D, Twagiramungu $\mathbf{H}$, Morin N, Brisson C, Carboneau G, Durocher J. 1999. In vitro embryo production in the cow: An effective alternative to the conventional embryo production approach. Theriogenology, 51:59-70.

Burns GW, Brooks KE, Spencer TE. 2016. Extracellular vesicles originate from the conceptus and uterus during early pregnancy in sheep. Biol Reprod, 56:1-11. doi: 10.1095/biolreprod.115.134973.

Burns GW, Brooks KE, O'Neil EV, Hagen DE, Behura SK, Spencer TE. 2018. Progesterone effects on extracellular vesicles in the sheep uterus. Biol Reprod, 98:612-622.

Cocucci E, Racchetti G, Meldolesi J. 2009. Shedding microvesicles: artefacts no more. Trends Cell Biol, 19:43-51.

da Silveira JC, Veeramachaneni DNR, Winger QA, Carnevale EM, Bouma GJ. 2012. Cell-secreted vesicles in equine ovarian follicular fluid contain miRNAs and proteins: A Possible New Form of Cell Communication Within the Ovarian Follicle. Biol Reprod, 86:71. doi: 10.1095/biolreprod.111.093252.

da Silveira JC, Carnevale EM, Winger QA, Bouma GJ. 2014. Regulation of ACVR1 and ID2 by cellsecreted exosomes during follicle maturation in the mare. Reprod Biol Endocrinol, 12:44. doi: 10.1186/1477-7827-12-44.

da Silveira JC, Andrade GM, Collado M, Sampaio RV, Pinaffi VLF, Jardim IB, Sangalli, JR, Silva LA, Cesar C, Nogueira MFG, Cesar ASM, Coutinho LL. 2017. Supplementation with small-extracellular vesicles from ovarian follicular fluid during in vitro production modulates bovine embryo development. PLoS ONE, 12:e0179451. doi: 10.1371/journal.pone.0179451. eCollection 2017.

Diez-Fraile A, Lammens T, Tilleman K, Witkowski W, Verhasselt B, De Sutter P, Benoit Y, Espeel M, D'Herde K. 2014. Age-associated differential microRNA levels in human follicular fluid reveal pathways potentially determining fertility and success of in vitro fertilization. Hum Fertil, 17:90-98.

Edson MA, Nagaraja AK, Matzuk MM. 2009. The mammalian ovary from genesis to revelation. Endocr Rev, 30:624-712.

El Andaloussi S, Manger I, Breakefield XO, Wood MJA. 2013. Extracellular vesicles: biology and emerging therapeutic opportunities. Nat Rev Drug 
Discov, 12:347-357.

Eriksen T, Terkelsen O, Hyttel P, Greve T. 1994. Anatomy and Embryology ultrastructural features of secretory cells in the bovine oviduct epithelium. Anat Embryol, 190:583-590.

Eyestone WH, First NL. 1989. Co-culture of early cattle embryos to the blastocyst stage with oviducal tissue or in conditioned medium. Reproduction, 85:715720 .

Farin CE, Imakawa K, Hansen TR, McDonnell JJ, Murphy CN, Farin PW, Roberts RM. 1990. Expression of trophoblastic interferon genes in sheep and cattle. Biol Reprod, 43:210-218.

Gould SJ, Raposo G. 2013. As we wait: coping with an imperfect nomenclature for extracellular vesicles. $J$ Extracell Vesicles, 2:20389. doi: 10.3402/jev.v2i0. 20389. eCollection 2013.

Greening DW, Nguyen HPT, Elgass K, Simpson RJ, Salamonsen LA. 2016. Human endometrial exosomes contain hormone-specific cargo modulating trophoblast adhesive capacity: insights into endometrial-embryo interactions. Biol Reprod, 94:38. doi 10.1095/biolreprod.115.134890.

György B, Szabó TG, Pásztói M, Pál Z, Misják P, Aradi B, László V, Pállinger É, Pap E, Kittel Á, Nagy G, Falus A, Buzás, EI. 2011. Membrane vesicles, current state-of-the-art: Emerging role of extracellular vesicles. Cell Mol Life Sci, 68:2667-2688.

Harding C, Heuser J, Stahl P, Harding C, Heuser J, Stahl P. 1983. Receptor-Mediated endocytosis of transferrin and recycling of the transferrin receptor in rat reticulocytes. J Cell Biol, 97:329-339.

Holm P, Callesen H. 1998. In vivo versus in vitro produced bovine ova: similarities and differences relevant for practical application. Reprod Nutr Dev, 38:579-594.

Hood JL, Wickline SA. 2012. A systematic approach to exosome-based translational nanomedicine. Wiley Interdiscip Rev Nanomed Nanobiotechnol, 4:458-467.

Hung WT, Hong X, Christenson LK, McGinnis LK. 2015. Extracellular vesicles from bovine follicular fluid support cumulus expansion. Biolo Reprod, 93:117.

Hung W, Navakanitworakul R, Kha, T, Zhang P, Davis JS, Mcginnis LK, Christenson LK. 2017. Stage-specific follicular extracellular vesicle uptake and regulation of bovine granulosa cell proliferation. Biol Reprod, 97:644-655.

Hunter RHF. 2012. Components of oviduct physiology in eutherian mammals. Biol Rev Camb Philos Soc, 87:244-255.

Knight PG, Glister C. 2006. TGF-beta superfamily superfamily members and ovarian follicle development. Reproduction, 132:191-206.

Kretser DM De, Hedger MP, Loveland KL, Phillips DJ. 2002. Inhibins, activins and follistatin in reproduction. Hum Reprod Update, 8:529-541.

Kropp J, Salih SM, Khatib H. 2014. Expression of microRNAs in bovine and human pre-implantation embryo culture media. Front Genet, 5:91. doi: 10.3389/fgene.2014.00091. eCollection 2014.

Kropp J, Khatib H. 2015a. Characterization of microRNA in bovine in vitro culture media associated with embryo quality and development. J Dairy Sci, 98:6552-6563.

Kropp J. Khatib H. 2015b. mRNA fragments in in vitro culture media are associated with bovine preimplantation embryonic development. Front Genet, 6:273. doi: 10.3389/fgene.2015.00273. eCollection 2015.

Kusama K, Nakamura K, Bai R, Nagaoka $K$, Sakurai T, Imakawa K. 2018. Intrauterine exosomes are required for bovine conceptus implantation. Biochem Biophys Res Commun, 495:1370-1375.

Leese HJ, Hugentobler SA, Gray SM, Morris DG, Sturmey RG, Whitear SL, Sreenan JM. 2008. Female reproductive tract fluids: composition, mechanism of formation and potential role in the developmental origins of health and disease. Reprod Fertil Devt, 20:18.

Lonergan P, Rizos D, Gutiérrez-Adán A, Moreira PM, Pintado B, de la Fuente J, Boland MP. 2003. temporal divergence in the pattern of messenger RNA expression in bovine embryos cultured from the zygote to blastocyst stage in vitro or in vivo. Biol Reprod, 69:1424-1431.

Lopera-vásquez R, Hamdi M, Fernandez-fuertes B, Maillo V. 2016. Extracellular vesicles from BOEC in in vitro embryo development and quality. PLoS ONE, 11:e0148083. doi: 10.1371/journal.pone.0148083. eCollection 2016

Lopera-Vasquez R, Hamdi M, Maillo V, GutierrezAdan A, Bermejo-Alvarez $P$, Angel Ramirez $M$, Yanez-Mo M, Rizos D. 2017. Effect of bovine oviductal extracellular vesicles on embryo development and quality in vitro. Reproduction, 153:461-470.

Lötvall J, Hill AF, Hochberg F, Buzás EI, Di Vizio D, Gardiner C, Gho YS, Kurochkin IV, Mathivanan S, Quesenberry $\quad$ P, Sahoo S, Tahara H, Wauben MH, Witwer KW, Théry C .2014. Minimal experimental requirements for definition of extracellular vesicles and their functions: A position statement from the International Society for Extracellular Vesicles. $J$ Extracell Vesicles, 3:26913. doi: 10.3402/jev.v3.26913. eCollection 2014

Maillo V, Lopera-Vasquez R, Hamdi M, GutierrezAdan A, Lonergan P, Rizos D. 2016. Maternal-embryo interaction in the bovine oviduct: Evidence from in vivo and in vitro studies. Theriogenology, 86:443-450.

Mathivanan S, Ji H, Simpson RJ. 2010. Exosomes: Extracellular organelles important in intercellular communication. J Proteomics, 73:1907-1920.

Matsuda F, Inoue N, Manabe N, Ohkura S. 2012. Follicular growth and atresia in mammalian ovaries: regulation by survival and death of granulosa cells. $J$ Reprod Dev, 58:44-50.

Mellisho EA, Vela AE, Cueto A, Fader C, Castro FO, Rodriguez-Alvarez L. 2017. Identification and characteristics of extracellular vesicles from bovine blastocysts produced in vitro. PLOS ONE, 12:e0178306. doi: 10.1371/journal.pone.0178306. eCollection 2017. Nakamura K, Kusama $K$, Bai R, Sakurai T, Isuzugawa $\mathrm{K}$, Godkin JD, Suda $\mathbf{Y}$, Imakawa $\mathrm{K}$. 2016. Induction of IFNT-Stimulated genes by conceptus-derived exosomes during the attachment 
period. PLoS ONE, 11:e0158278. doi: 10.1371/journal.pone.0158278. eCollection 2016.

Navakanitworakul R, Hung WT, Gunewardena S, Davis JS, Chotigeat W, Christenson LK. 2016. Characterization and small RNA content of extracellular vesicles in follicular fluid of developing bovine antral follicles. Sci Rep, 6:25486. doi: 10.1038/srep25486.

Ng YH, Rome S, Jalabert A, Forterre A, Singh H, Hincks CL, Salamonsen LA. 2013. Endometrial exosomes/microvesicles in the uterine microenvironment: a new paradigm for embryoendometrial cross talk at implantation. PLoS ONE, 8:e58502. doi: 10.1371/journal.pone. 0058502 .

Nguyen J, Szoka FC. 2012. Nucleic acid delivery: the missing pieces of the puzzle? Acc Chem Res, 45:11531162.

Orsi NM, Reischl JB. 2007. Mammalian embryo coculture: Trials and tribulations of a misunderstood method. Theriogenology, 67:441-458.

Pan BT, Teng K, Wu C, Adam M, Johnstone RM. 1985. Electron microscopic evidence for externalization of the transferrin receptor in vesicular form in sheep reticulocytes. J Cell Biol, 101:942-948.

Pavani KC, Alminana C, Wydooghe E, Mermillod P, Catteeuw M, Ramírez MA, Rizos D, Soom A Van. 2017. Emerging role of extracellular vesicles in communication of preimplantation embryos in vitro. Reprod Fertil Dev, 29:66-83.

Plante L, King WA. 1994. Light and electron microscopic analysis of bovine embryos derived by in Vitro and in Vivo fertilization. J Assist Reprod Genet, 11:515-529.

Qu P, Qing S, Liu R, Qin H, Wang W, Qiao F, Ge H, Liu J, Zhang Y, Cui W, Wang Y. 2017. Effects of embryo-derived exosomes on the development of bovine cloned embryos. PLOS ONE, 12:e0174535. doi: 10.1371/journal.pone.0174535. eCollection 2017.

Raposo G, Stoorvogel W. 2013. Extracellular vesicles: Exosomes, microvesicles, and friends. $J$ Cell Biol, 200:373-383.

Rizos D, Fair T, Papadopoulos S, Boland MP, Lonergan P. 2002a. Developmental, qualitative, and ultrastructural differences between ovine and bovine embryos produced in vivo or in vitro. Mol Reprod Dev, 62:320-327.

Rizos D, Ward F, Duffy P, Boland MP, Lonergan P. $2002 \mathrm{~b}$. Consequences of bovine oocyte maturation, fertilization or early embryo development in vitro versus in vivo: Implications for blastocyst yield and blastocyst quality. Mol Reprod Dev, 61:234-248.

Ruiz-González I, Xu J, Wang X, Burghardt RC, Dunlap KA, Bazer FW. 2015. Exosomes, endogenous retroviruses and toll-like receptors: pregnancy recognition in ewes. Reproduction, 149:281-291.

Saadeldin IM, Kim SJ, Choi YB, Lee BC. 2014. Improvement of cloned embryos development by coculturing with parthenotes: a possible role of exosomes/microvesicles for embryos paracrine communication. Cell Reprogram, 16:223-234.
Saadeldin IM, Oh HJ, Lee BC. 2015. Embryonic maternal cross-talk via exosomes: potential implications. Stem Cells Cloning, 8:103-107.

Simpson RJ, Jensen SS, Lim JWE. 2008. Proteomic profiling of exosomes: Current perspectives. Proteomics, 8:4083-4099.

Sirard MA. 2018. 40 years of bovine IVF in the new genomic selection context. Reproduction, 156:R1-R7. doi: 10.1530/REP-18-0008.

Sohel MMH, Hoelker M, Noferesti SS, SalilewWondim D, Tholen E, Looft C, Rings F, Uddin MJ, Spencer TE, Schellander K, Tesfaye D. 2013. Exosomal and non-exosomal transport of extra-cellular microRNAs in follicular fluid: Implications for bovine oocyte developmental competence. PLoS ONE, 8:e78505. doi: 10.1371/journal.pone.0078505. eCollection 2013

Spencer TE, Bazer FW. 2002. Biology of progesterone action during pregnancy recognition and maintenance of pregnancy. Front Biosci, 7:d1879-1898.

Subra C, Laulagnier K, Perret B, Record M. 2007. Exosome lipidomics unravels lipid sorting at the level of multivesicular bodies. Biochimie, 89:205-212.

Tannetta D, Dragovic R, Alyahyaei Z, Southcombe J. 2014. Extracellular vesicles and reproductionpromotion of successful pregnancy. Cell Mol Immunol, 11:548-563.

Théry C, Ostrowski M, Segura E. 2009. Membrane vesicles as conveyors of immune responses. Nat Rev Immunol, 9:581-593.

Théry C, Zitvogel L, Amigorena S. 2002. Exosomes: composition, biogenesis and function. Nat Rev Immunol, 2:569-579.

Urrego R, Rodriguez-Osorio N, Niemann H. 2014. Epigenetic disorders and altered gene expression after use of assisted reproductive technologies in domestic cattle. Epigenetics, 9:803-815.

Valadi H, Ekström K, Bossios A, Sjöstrand M, Lee JJ, Lötvall, JO. 2007. Exosome-mediated transfer of mRNAs and microRNAs is a novel mechanism of genetic exchange between cells. Nat Cell Biol, 9:654-659.

Witwer KW, Buzás EI, Bemis LT, Bora A, Lässer C, Lötvall J, Nolte-'t Hoen EN, Piper MG, Sivaraman S, Skog J, Théry C, Wauben MH, Hochberg F. 2013. Standardization of sample collection, isolation and analysis methods in extracellular vesicle research. $J$ Extracell Vesicles, 2:1-25. doi: 10.3402/jev.v2i0.20360. eCollection 2013.

Zhang H, Freitas D, Kim HS, Fabijanic K, Li Z, Chen H, Mark MT, Molina H, Martin AB, Bojmar L, Fang J, Rampersaud S, Hoshino A, Matei I, Kenific CM, Nakajima M, Mutvei AP, Sansone P, Buehring W, Wang H, Jimenez JP, Cohen-gould L, Paknejad $\mathbf{N}$, Brendel $M$, Manova-todorova $K$, Cubillos-ruiz JR, Galletti G, Giannakakou P, Cuervo AM. 2018. Identification of distinct nanoparticles and subsets of extracellular vesicles by asymmetric flow field-flow fractionation. Nat Cell Biol, 20:332-343. 